\title{
Commentary: The heartburn of lung transplantation
}

\author{
Ross M. Bremner, MD, PhD
}

During the past 2 decades, we have become more aware of the relationship between gastroesophageal reflux disease (GERD) and chronic rejection after lung transplant. As mentioned by Davidson and colleagues ${ }^{1}$ in their article in this issue of the Journal, the mechanisms of rejection are not well understood and are likely multifactorial. Conceptually, aspiration into the transplanted lung of reflux of gastric contents initiates an inflammatory cascade that can provoke chronic rejection. It thus stands to reason that a laparoscopic antireflux procedure to correct GERD can reduce the reflux of gastric contents, and increasing evidence suggests that such a procedure may be protective posttransplant. Unfortunately, we have no exact means of quantifying the risk of aspiration after transplant; however, a high DeMeester score-especially in the proximal esophagus-and poor esophageal and gastric motility are surrogates for increased risk. Eating late at night, lying flat when sleeping, and sedative use may thwart the arousal mechanism. The loss of the cough reflex from the denervated lung likely also contributes. There is something that may be unique when discussing GERD and lung transplant, however, because it may only take a single episode of aspiration to initiate the inflammatory cascade-although, again, this is not well understood.

The picture is further complicated by the fact that we do not yet have a precise, noninvasive way to detect very early rejection. A decrease in forced expiratory volume in 1 second $\left(\mathrm{FEV}_{1}\right)$ has been used as an indicator of declining lung function that raises the suspicion of rejection. Some have suggested that the inflammatory cascade has already begun by the time that $\mathrm{FEV}_{1}$ noticeably declines in patients with GERD, and that it therefore may be too late for a fundoplication to make much difference. Indeed, our group has reported that early

\footnotetext{
From the Norton Thoracic Institute, St Joseph's Hospital and Medical Center, Phoenix, Ariz

Disclosures: Author has nothing to disclose with regard to commercial support.

Received for publication Nov 19, 2019; accepted for publication Nov 19, 2019; available ahead of print Dec 9, 2019.

Address for reprints: Ross M. Bremner, MD, PhD, Norton Thoracic Institute, St Joseph's Hospital and Medical Center, $500 \mathrm{~W}$ Thomas Rd, Suite 500, Phoenix, AZ 85013 (E-mail: Ross.Bremner@DignityHealth.org).

J Thorac Cardiovasc Surg 2020;160:867

$0022-5223 / \$ 36.00$

Copyright (c) 2019 by The American Association for Thoracic Surgery

https://doi.org/10.1016/j.jtcvs.2019.11.091
}

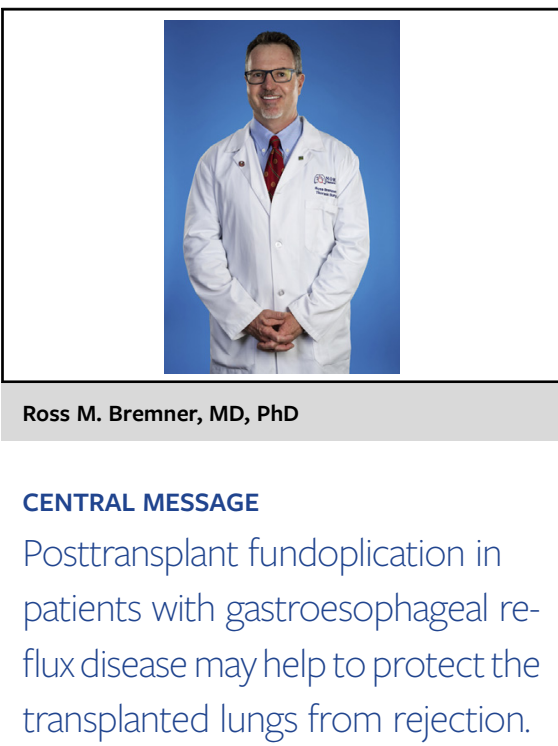

fundoplication posttransplant in patients with GERD appears to be more protective than later fundoplication. ${ }^{2}$ Yet there is hope! The current article by Davidson and colleagues ${ }^{1}$ has summarized all the available published data to address the burning question: Is fundoplication after $\mathrm{FEV}_{1}$ decline too little, too late? Davidson and colleagues ${ }^{1}$ have concluded that, even when a fundoplication is performed after $\mathrm{FEV}_{1}$ begins to decline, the procedure still plays an important role in protecting the transplanted organ from further damage. In fact, the rate of $\mathrm{FEV}_{1}$ decline plateaus and may even improve after fundoplication. This is indeed very encouraging - and the work is critical as we struggle to improve 5-year survival statistics for lung transplant recipients.

This article provides a strong argument for the careful evaluation of all lung transplant recipients for GERD, and to consider antireflux surgery in patients with significantly elevated $\mathrm{pH}$ scores, as well as those who are predisposed to aspiration. We believe that the antireflux procedure should be done early whenever possible; even when it is carried out later, however, the work presented here shows that it still carries significant value. Davidson and colleagues ${ }^{1}$ are to be congratulated and thanked for their work with the available published data, which has helped us to understand this difficult problem a little better.

\section{References}

1. Davidson JR, Franklin D, Kumar S, Mohammadi B, Dawas K, Eaton S, et al. Fundoplication to preserve allograft function after lung transplant: Systematic review and meta-analysis. J Thorac Cardiovasc Surg. 2020;160:858-66.

2. Biswas Roy S, Elnahas S, Serrone R, Haworth C, Olson MT, Kang P, et al. Early fundoplication is associated with slower decline in lung function after lung transplantation in patients with gastroesophageal reflux disease. J Thorac Cardiovasc Surg. 2018;155:2762-71.e1. 